\title{
ARTÍCULO
}

\section{La actualidad de la equidad de Aristóteles. Doce tesis antiformalistas sobre el derecho y la función judicial ${ }^{\alpha}$}

\author{
Jesús Vega \\ Departamento de Filosofía del Derecho y Derecho Internacional Privado \\ Universidad de Alicante
}

Fecha de recepción: 13/01/2014 | De aceptación: 04/06/2014 | De publicación: 24/06/2014

\section{RESUMEN.}

En este trabajo se propone una lectura de la teoría aristotélica de la equidad desde los presupuestos de un enfoque argumentativo del derecho. Después de ofrecer una contextualización de la filosofía del derecho de Aristóteles en el marco de su filosofía moral (teoría de la virtud) y política (teoría del Estado), se extraen las implicaciones de la equidad para la práctica de la jurisdicción en forma de doce tesis críticas del formalismo jurídico.

PALABRAS CLAVE.

Equidad, Aristóteles, argumentación, formalismo jurídico, Estado de derecho

\section{ABSTRACT.}

This paper purports an interpretation of the Aristotelian theory of equity from the point of view of an argumentative approach to law. Once the main ideas of the legal philosophy of Aristotle are framed in the context of his moral and political philosophy (namely, virtue theory and state theory), the implications of equity for the practice of judicial reasoning are drawn in the form of twelve theses against legal formalism.

KEY WORDS.

Equity, Aristotle, argumentation, legal formalism, rule of law

"Este trabajo ha sido realizado en el marco del proyecto de investigación Constitucionalismo y argumentación (DER201020132) financiado por el Ministerio de Ciencia e Innovación. 
Cuadernos Electrónicos de Filosofía del Derecho

1. Aristóteles y la filosofía del derecho. 2. Los temas de la equidad. 3. Ad i) El derecho y la virtud de la justicia. 4.

Ad ii) Justicia e igualdad. Tres dimensiones de la igualdad. 5. Ad iii) La continuidad entre legislación y jurisdicción. 6. Doce tesis antiformalistas derivadas de la equidad aristotélica. 7. Referencias

\section{Aristóteles y la fillosofía del derecho}

La equidad es una de las ideas centrales de la filosofía aristotélica del derecho: una de esas ideas que -como la de prudencia o la de justicia - han recorrido toda la historia del pensamiento jurídico y no sólo llegan a nosotros sino que continúan interpelándonos con una fuerza y una actualidad verdaderamente asombrosas. Con ello demuestran por qué provienen de un clásico de la filosofía práctica: pues los clásicos, en palabras de I. Calvino, nunca terminan de decir lo que tienen que decir. Lo que intentaré mostrar en las páginas que siguen es que efectivamente las reflexiones de Aristóteles sobre la equidad, aunque sigan expresando lo mismo de siempre, siguen teniendo cosas nuevas que decir a la altura de la filosofía del derecho del s. XXI.

Resulta muy difícil caer en la exageración a la hora de valorar la importancia de Aristóteles para la cultura jurídica. Hace unas décadas, en ciertas corrientes de la filosofía europea se puso de moda un eslogan - "rehabilitación de la filosofía práctica"- que, entre otras cosas, pretendía volver la vista hacia la filosofía aristotélica $^{1}$. Sin embargo, si hablamos de la filosofía del derecho — que es una pieza angular de esa filosofía práctica- podría muy bien decirse que la impronta del pensamiento aristotélico es tan profunda que en realidad no ha necesitado nunca ser rehabilitado a fuer de hacerse ubicua, y por ello mismo invisible, su presencia. No hablo solamente de las últimas corrientes autodenominadas "neoaristotélicas", ni del resurgimiento de nuevas aproximaciones a la tópica o a la retórica, de la virtue jurisprudence, etc., por no mencionar — claro está- la gran teoría escolástico-iusnaturalista, que se construyó históricamente sobre moldes aristotélicos (si era verdaderamente "aristotélica" o no es otro asunto) y llegó a ser dominante durante tantos siglos en nuestra tradición. Me estoy refiriendo sobre todo al hecho de que Aristóteles desarrolló una concepción del derecho desde la perspectiva de su filosofía práctica — de su concepto de "razón práctica": otra idea suya decisiva que transita toda la historia de la filosofía - de la que cabría decir con toda exactitud que posee un carácter basal para la tradición de la teoría jurídica. Lo que quiero decir con esto es que se trata de una

${ }^{1}$ Cf. VOLPI, F., "Rehabilitación de la filosofía práctica y neo-aristotelismo", Anuario Filosófico, 1999/32: 315-342 (trad. R. Vigo). Sobre el "giro aristotélico", WALLACH, J. R., "Contemporary Aristotelianism", Political Theory, 20/4 (1992), pp. 613-641. 
Cuadernos Electrónicos de Filosofía del Derecho

concepción que ha pasado a formar parte del acervo básico - de los fundamentos- de cualquier otra concepción del derecho ulterior, incluyendo aquellas de signo contrario que han desarrollado esos fundamentos según direcciones distintas o los han envuelto bajo concepciones filosóficas diferentes, comportándose así como una suerte de "variaciones" compuestas o interpretadas a partir de un mismo teclado conceptual. En este sentido podría decirse de Aristóteles lo que Hegel decía de Spinoza: que todo el mundo tiene dos filosofías del derecho, la suya y la de Aristóteles. Elementos de esa concepción básica — piezas de ese "teclado"son:

a) en primer lugar, su teoría de la legislación: la doctrina del nomos en la que se apoya su tesis racionalista del "gobierno de las leyes y no de los hombres", es decir, del imperio de la ley: lo que siglos más tarde se llamará el "Estado de derecho";

b) en segundo lugar, su teoría de la jurisdicción o aplicación circunstanciada prudencial_ a los casos particulares de las normas generales en que (necesariamente) consiste el nomos; teoría ésta que no sólo tiene una dimensión metodológica (es la primera formulación sistemática de las pautas de interpretación del derecho: no por casualidad al Estagirita se le ha llamado el "primer maestro de metodología jurídica"²) sino que constituye también una explicación profunda de la razón de ser de la propia institución jurisdiccional como parte integrante de todo sistema jurídico;

c) en tercer lugar, la tesis de que el derecho es una práctica institucional compleja en la que se da una continuidad peculiar entre las dos instituciones que acabamos de mencionar: legislación y jurisdicción;

d) en cuarto lugar, la tesis acerca de la racionalidad de esa práctica, esto es, acerca de su carácter esencialmente argumentativo y justificativo: la visión del derecho como un sistema de razonamientos prácticos (no sólo de normas o proposiciones ni de decisiones o actos coactivos); $\mathrm{y}$

e) por último, la tesis de la contextualización moral y política de la institución jurídica, cuya normatividad tiene una función "arquitectónica", de puente intermediario entre la moralidad y la organización pública del Estado - la comunidad política-, que conecta necesariamente la teoría del derecho con la teoría de la virtud y la teoría de los regímenes políticos.

Todos estos puntos se hallan sólidamente ensamblados entre sí, como lo están la filosofía política y moral dentro del conjunto de la filosofía práctica aristotélica. Pero — cabe sostener- es en

\footnotetext{
${ }^{2}$ ADOMEIT, K. y HERMIDA, C., Filosofia del Derecho y del Estado. De Sócrates a Séneca [1992], Madrid, Trotta, 1999, p. 104.
} 
Cuadernos Electrónicos de Filosofía del Derecho

la filosofía jurídica donde se manifiestan las verdaderas proporciones de ese ensamblaje: y, precisamente, en la teoría de la equidad o epieikeia, de la que aquí nos ocuparemos. Pues si en la tradición se ha tendido a subsumir las reflexiones aristotélicas sobre el legislador y el juez bajo las categorías generales de su filosofía política y su filosofía moral, disolviendo así la especificidad jurídica de las mismas, la teoría de la equidad invita a recorrer en cambio el camino inverso. En efecto, ésta nos muestra la práctica de la jurisdicción — pues es el juez de quien se predica por antonomasia la equidad - como aquel punto de apoyo o soporte fundamental de la propia práctica de la legislación y, por tanto, de la política misma, del "gobierno de las leyes" en su integridad. Ambas consisten - como formas de praxis que son- en instituciones que guían conjuntamente la acción (la acción colectiva), pero lo hacen no de cualquier modo sino guiándose a su vez por ciertos ideales y valores y, por tanto, bajo la luz de la virtud, esto es, de la justicia, aspecto que se visibiliza de modo especialmente claro en la posición y la acción (individual, en este caso, pero formando parte de una institución) del juez.

Acaso por el acento que sobre esos ideales morales y políticos ponía ya su poderosa filosofía moral y política, Aristóteles no consideró necesario desarrollar una filosofía del derecho diferenciada, lo cual alimentó la propensión a sumergirla bajo aquélla y con ello a minusvalorar su importancia propia y específica. La concepción filosófico-jurídica del Estagirita está contenida en forma implícita y dispersa en sus escritos, diseminada a lo largo de la Ética a Nicómaco, la Política y la Retórica ${ }^{3}$. De ello resulta que tal concepción tiene que ser reconstruida interpretativamente, hallándose, por consiguiente, abierta a distintas lecturas cada una de las cuales dependerá de los supuestos hermenéuticos asumidos en cada ocasión por el intérprete y su propia filosofía. Esto no es novedad alguna: siempre ha sido así. Sabemos, por ejemplo, sin ir más lejos, que las dos grandes concepciones tradicionales de la filosofía jurídica, el positivismo jurídico y el iusnaturalismo, suelen reconducirse en sus orígenes a los textos aristotélicos, especialmente a su célebre distinción entre "justicia legal" y "justicia natural" (Ética nicomáquea, V, 7), donde ha solido verse la primera formulación sistemática de la distinción entre "derecho positivo" y "derecho natural" (de ahí eso que antes decíamos acerca de que el pensamiento aristotélico ha representado un auténtico vivero histórico de ideas para la filosofía del derecho). La interpretación que pretendo defender aquí asume, sin embargo, que

\footnotetext{
${ }^{3}$ Cf. MILLER, F. D., "Aristotle's Philosophy of Law", en F. D. MILLER, P. G. STEIN y A. PADOVANI (eds.), $A$ History of the Philosophy of Law from the Ancient Greeks to the Scholastics, Dordrecht, Reidel, 2007, pp. 79-110.
} 
Cuadernos Electrónicos de Filosofía del Derecho

la teoría del derecho de Aristóteles no es ni iuspositivista ni iusnaturalista. Tal interpretación se mantiene más bien dentro de los marcos de la concepción del derecho que hoy llamamos "argumentativa", "post-positivista" o "constitucionalista", desarrollada en las últimas décadas por autores como Dworkin, Alexy, Nino o Atienza, y caracterizada, entre otras cosas, por la pretensión de superar esa dicotomía tradicional (iusnaturalismo-iuspositivismo) y de recuperar precisamente algunos de esos elementos que hemos considerado basales de la concepción aristotélica: fundamentalmente, la consideración del derecho como una práctica, el énfasis en la argumentación y la razón práctica, la conexión entre derecho, moral y política. Sostengo que sólo una concepción de este tipo sería, debido a tal enfoque, adecuada para lograr con éxito esa reconstrucción buscada de la filosofía del derecho aristotélica. Sostengo, además, que ella es también la única que permite poner de manifiesto un hecho que ha solido ser descuidado en las interpretaciones filosóficas de Aristóteles: que el derecho es una clave articuladora esencial de toda su filosofía práctica, un hecho que los juristas (por razón de escala o perspectiva) estarían especialmente bien situados para percibir y apreciar (muchas veces incluso mejor que los filósofos morales o políticos). Un marco filosófico-jurídico de esta índole es el único que permite entender — tal es mi tesis - el sentido auténtico de la idea aristotélica de equidad y de este modo transitar ese camino inverso que, según decíamos, ella marca como una especie de hilo rojo que va de la práctica del juez a la práctica del legislador (al "gobierno de las leyes" o Estado de derecho) y liga ambas con la justicia (o sea, con ciertos valores político-morales).

\section{Los temas de la equidad}

Si uno repasa los apenas tres párrafos en que convencionalmente se divide el célebre pasaje sobre la equidad de la Ética nicomáquea (el Cap. 10 del Libro V), lugar donde Aristóteles sistematiza su concepción definitiva al respecto tras las reflexiones de la Retórica (I, 13, 3, 1374a27-1374b2; 1374b11-16), se topa con al menos tres nudos principales de su argumentación. Pueden resumirse así:

i) En primer lugar, Aristóteles suscita (en el primer párrafo) el problema de las relaciones entre equidad y justicia. La equidad aparece desde el inicio como una idea que cae dentro de la órbita de la justicia, que pertenece al género de lo justo: es una forma de justicia ("lo mismo es, por tanto, lo justo y lo equitativo", $1137 \mathrm{~b} 10)^{4}$, pero es $\sin$ embargo mejor que la justicia. Esto se formula como un problema, una paradoja (¿cómo es posible que la equidad sea justa y al mismo

\footnotetext{
${ }^{4}$ Cito según la ed. de M. Araujo y J. Marías (Madrid, CEPC, 2009, $9^{\text {a }}$ ed.).
} 
Cuadernos Electrónicos de Filosofía del Derecho

tiempo mejor que lo justo?), paradoja que se retrotrae a un tema platónico en cuyo detalle no podemos entrar ahora y que Aristóteles resuelve de dos modos: primero, negando que esa mejor forma de justicia pertenezca a otro género (un género que esté más allá de la justicia) y, segundo, afirmando que existen dos especies de justicia dentro de ese género: la justicia según la ley (la justicia legal) y la justicia según la equidad (consistente en la corrección de la anterior). Este primer punto nos exige aclarar las relaciones entre justicia y derecho, pues como vemos la idea de justicia —que podría pensarse que es una idea "puramente moral", en el sentido de extrajurídica - está introduciéndonos de lleno en la institución del derecho, en la legalidad y en la aplicación de la legalidad.

ii) A continuación, en el segundo párrafo, nos habla Aristóteles del legislador: de la ley como parte del derecho, de algunas características de la práctica de legislar, del razonamiento legislativo (o incluso la técnica legislativa diríamos hoy). Entre esas características sobresale una que conlleva que el legislador incurre en un error, un déficit o una insuficiencia. De aquí arranca la necesidad de la corrección en que consiste la equidad. $\mathrm{Y}$ ese error o deficiencia se pone en conexión con el carácter universal de la ley: "La causa de ello es que toda ley es universal, y hay cosas que no se pueden tratar rectamente de un modo universal. En aquellos casos, pues, en que es preciso hablar de un modo universal, pero no es posible hacerlo rectamente, la ley toma en consideración lo más corriente, sin desconocer su yerro" (1137b13-17). Este segundo punto nos llevará a reconstruir la teoría aristotélica de la legalidad, el papel de las leyes, del nomos, su carácter universal del que depende la apología del imperio de la ley, y los fundamentos de tal universalidad (que se anclan en la organización política - pues para Aristóteles sin leyes no hay constitución política o Estado en absoluto- y también en la moral, en la virtud, pues de ahí arranca la validez de las leyes). Pero también nos llevará a su teoría de la práctica (ya que a fin de cuentas el "error" no se imputa a la ley ni al legislador, sino a la "naturaleza de la práctica" [1137b19-20]) y, en particular, a dilucidar las relaciones entre la práctica del legislador y la práctica del juez dentro del derecho.

iii) Por último, tercer párrafo, Aristóteles nos habla no del legislador sino del juez. Es al juez a quien incumbe corregir ese error, quien debe aplicar un juicio de equidad en el caso particular capaz de subsanar la insuficiencia en que ha incurrido el legislador: "Por tanto, cuando la ley se expresa universalmente y surge a propósito de esa cuestión algo que queda fuera de la formulación universal, entonces está bien, allí donde no alcanza el legislador y yerra al simplificar, corregir la omisión" (1137b20-23). Y 
Cuadernos Electrónicos de Filosofía del Derecho

también nos dice cómo ha de hacerlo, esto es, el método que el juez debe seguir para corregir ese error: que consiste en recurrir a "aquello que el legislador mismo habría establecido en su ley si hubiera conocido el caso" (1137b23-24, modifico la traducción). Es así como - concluye Aristóteles cerrando el punto inicial - la equidad es justa y al mismo tiempo mejor justicia: o sea, "mejor que una clase de justicia [i.e., la justicia legal]; no que la justicia absoluta, pero sí que el error producido por el carácter absoluto de la ley" (1137b24-26, id.). "Y esta es la naturaleza de la equidad: una corrección de la ley cuando ésta es deficiente debido a su universalidad" (1137b2627, esta frase del texto aristotélico está sin traducir en la versión citada de Marías/Araujo). Finaliza Aristóteles con la célebre metáfora, de enorme fuerza expresiva, que compara a las normas jurídicas con reglas de plomo ("tratándose de lo indefinido, la regla es también indefinida, como la regla de plomo de los arquitectos lesbios, que se adapta a la forma de la piedra y no es rígida" (1137b30-32). En este tercer punto el foco se centra, pues, en la institución de la jurisdicción, la práctica del juez y su coordinación con la práctica legislativa, tanto desde un punto de vista "técnico-metodológico" (los métodos de interpretación: literal, formulación de la ley, y teleológica, las razones de la ley) como sobre todo desde un punto de vista institucional: qué función desempeña la autoridad (y el poder político) del juez dentro del conjunto del derecho, cómo se organiza la "división del trabajo jurídico". Ambas cosas son indesligables, en el planteamiento aristotélico (y en ello reside su interés y actualidad) de la dimensión valorativa, justificativa y moral de la práctica judicial dicho de otro modo: del ideal del buen juez- que se revela ocupando un lugar central en el diseño del Estado de derecho.

Pongamos entonces sumariamente contexto a cada uno de estos puntos antes de extraer las implicaciones que encierra la equidad para la comprensión de la práctica judicial y, a su través, del derecho en su conjunto.

\section{Ad i) El derecho y la virtud de la justicia}

Comenzaremos por las relaciones entre derecho y justicia. Puesto que la justicia es una virtud, debemos decir antes de nada algunas cosas muy rápidas acerca de esta idea, la idea nuclear de la Ética, y acerca del tipo de racionalidad que comporta. Las virtudes son entendidas por Aristóteles como disposiciones recursivas $\mathrm{o}$ "modos de ser" (hexeis) del obrar humano orientadas a la excelencia: a la eupraxia, la buena acción. O sea, diríamos hoy, orientadas por valores. La idea de valor no está formulada explícitamente en Aristóteles - la axiología es una doctrina fundamentalmente moderna- pero sí presupuesta y ejercitada en su obra moral (en 
Cuadernos Electrónicos de Filosofía del Derecho

todo caso, lo está también en su teoría de la justicia, al hablar de los parámetros de la distribución (axia) y los criterios de la reparación del daño, o en su pionera teoría del dinero ligada a la justicia conmutativa y recíproca). La virtud es un término medio entre dos extremos (dos vicios o disvalores: por ejemplo, la valentía es intermedia a la cobardía y a la temeridad, la generosidad a la prodigalidad y a la tacañería), término medio cuyo valor proviene de venir determinado por la razón (de ser un balance universalizable, por tanto) y también por la prudencia, es decir, de ser el mejor balance relativo a la situación concreta en que se actúa (II, 6). Lo decisivo es cómo se entiende ese concepto de razón. Aristóteles lo considera indisociable de alguna clase de deliberación a cargo del sujeto (en términos que hoy llamaríamos constructivistas) que arroja "razones para la acción” (por usar otra expresión contemporánea). Tal deliberación es analogada con la epistēmē, con el modelo de la ciencia, de la razón "teorética": una analogía que subraya semejanzas pero también diferencias decisivas. El resultado es un peculiar racionalismo práctico que permite a Aristóteles terciar entre el intelectualismo socrático-platónico (la "ciencia de la virtud”) y el escepticismo relativista de los sofistas. Así se construye el concepto de "razón práctica": existe racionalidad en la acción humana, regida por valores objetivos (éstos no son pues inanes, contra los sofistas), pero no al modo de la ciencia (contra Platón), sino al modo de la prudencia. Ésta, la phronēsis, tiene que ver con la realización circunstancial y constante (de ahí la idea de una disposición recursiva o hábito) del bien práctico, de los principios de la acción correcta, en aquellas cosas que no son necesarias (como ocurre en la ciencia y en la técnica), sino contingentes, que "pueden ser de modo distinto a como son" porque dependen precisamente de nuestra deliberación y nuestra acción ${ }^{5}$. De manera que el razonamiento práctico (el "silogismo práctico"), que opera en términos de medios-fines a partir de las prácticas humanas materiales, genera además (cuando hablamos de la moral o la política) razones formales o de segundo orden desde las cuales, en el logos o intercambio discursivo (que implica el elogio y la censura), se establece la corrección y valor de aquellas prácticas. Estas razones operan así como reglas que establecen la recurrencia de las mismas en cuanto que realizan o ponen en obra ciertos valores frente a disvalores contrapuestos. El "silogismo" práctico aparece como un modo de representar la acción humana bajo el cual ésta consistiría en emprender, partiendo de situaciones concretas, una deliberación acorde con fines, reglas y valores

\footnotetext{
${ }^{5}$ Cf. Ét. Nic., III, 3. P. AUBENQUE, La prudencia en Aristóteles [1963], trad. de M ${ }^{\mathrm{a}}$. J. Torres, Barcelona, Crítica, 1999, pp. 105ss.
} 
Cuadernos Electrónicos de Filosofía del Derecho

(que implican así un elemento universal) para volver a la acción particular mediante una decisión (prohairesis) elegida y puesta en práctica por el individuo. Es así un razonamiento que individualiza (mediante la prudencia) criterios que se entienden como objetivos y universales, un logos racional, pero que es racional justamente (y esta es la diferencia crucial con la epistèmēe) en la medida en que conduce a generar cursos persistentes de acción, hábitos buenos (sólo practicando el bien nos hacemos buenos, dice Aristóteles, y la ética no es una reflexión para conocer el bien sino para hacernos buenos). Simplificando mucho, es esto a fin de cuentas lo que quiere decir que la moral y la política constituyen ambas variantes de praxis: prácticas deliberativas virtuosas, regida por bienes o valores racionalmente establecidos. Retener esta idea es crucial para entender apropiadamente el concepto de equidad.

La equidad es también una virtud, puesto que es una forma de justicia. Pero la justicia no es una virtud más sino la virtud suprema, a cuyo análisis dedica el libro $\mathrm{V}$ de la Ética, punto de inflexión cardinal en la obra y uno de los más difíciles de interpretar. La supremacía de la justicia proviene de ser una virtud de segundo orden, que supone la transición desde la moral (desde las demás virtudes: digamos, del "hombre bueno", el phronimos o el spoudaios) a la política (al "buen ciudadano"). Y de aquí arranca también la conexión conceptual entre derecho y justicia: porque ese tránsito de la ética a la política está realizado precisamente por la ley, por la institucionalización del aparato jurídico. Por eso la justicia es la virtud característicamente jurídica: la virtud específica del derecho. Siendo, como toda virtud, una excelencia de la acción que maximiza valores, se trata ahora específicamente de la acción de los operadores jurídicos (los legisladores y los jueces), que son aquellas autoridades de las cuales depende la organización y el buen orden (la eutaxia) de la polis, de la comunidad política, y aquellos sujetos que practican "las cosas justas", es decir, quienes hacen justicia (que es entonces virtud también indesligablemente política). "La virtud de la justicia [dikaiosynē] pertenece a la polis, pues la justicia es el orden de la comunidad política [politikēs koinōnias taxis] y la virtud de la justicia es el conjunto de juicios que establecen lo que es justo [dikaiou krisis]" (Política, I, 2, 1253a37-39, trad. propia).

Después de discutir la pluralidad de sentidos en que se ha hablado de justicia (ya la Ética daba comienzo levantando acta de la homonimia del bien: "el bien se dice de muchas maneras"), Aristóteles ofrece esta aparente definición: "lo justo es lo legal y lo igual (to nomimon kai to ison)" (V, 1, 1129a34). Define así la justicia por respecto a la ley, a la legalidad, 
Cuadernos Electrónicos de Filosofía del Derecho

al nomos, y por respecto a la idea de igualdad. Esta clase de justicia es la que se ha llamado tradicionalmente justicia general o universal (en contraposición a la justicia particular en sus dos especies, distributiva y correctiva), si bien a veces se identifica la justicia universal con la legalidad y la particular con la igualdad. Detengámonos en este par de ideas, legalidad e igualdad, que como es fácil intuir remiten (igual que toda virtud) a valores: aquí, al valor de la legalidad o "justicia formal" o "seguridad jurídica", por un lado, y al valor de la justicia material o — como veremosde la equidad, por otro. ¿Cómo se relacionan entre sí? ¿Cuál de ellos es más decisivo? ¿Qué relación mantienen con la distinción entre la justicia legal y la equidad como corrección de la misma?

Antes de responder a esas preguntas debemos contestar a una más general: ¿no implica una flagrante circularidad remitir desde un principio el derecho a la justicia para acabar reenviando la justicia al derecho, a lo conforme con la legalidad? Veremos que en absoluto es así. Se trata de ver las relaciones entre ambos como la circularidad del proceso de construcción del derecho como una práctica compleja de alcance político-moral. Desde luego, la posición de Aristóteles no es lo que hoy llamaríamos un positivismo ideológico, que identifica la justicia con lo que establece el derecho positivo (aunque así ha sido visto a veces: por Kelsen, p. ej.).
Aristóteles afirma que lo legal es justo "en un cierto sentido" (Ét. Nic., V, 1, 1129b11), es decir, se está refiriendo a las leyes bien establecidas (la eunomia), las leyes que (dicho en términos actuales) satisfacen la pretensión de corrección. Para entender esto debemos regresar a la idea de que las leyes cumplen un papel de puente entre la moralidad y la política. Las leyes son, en efecto, los instrumentos vertebradores del orden (taxis) de la comunidad política. Este orden no es originario, ni se establece a partir de un grado cero, sino en términos de una totalización de segundo grado que refunde normas y valores previamente dados (los que rigen las comunidades prepolíticas a partir de las cuales se construye el Estado: familias, villas, etc.), característica que Aristóteles expresa llamando "arquitectónica" a la labor legislativa y que está en correspondencia histórica con lo que suele llamarse el paso del thesmos (norma tradicional) al nomos (norma revestida de autoridad política central). Dicha totalización supone que las leyes se refieren "a todas las materias" (esto es, poseen carácter exhaustivo respecto de todo el dominio de las prácticas sociales) y apuntan al "interés común de todos" (V, 1, 1129b14-15). Por lo tanto el nomos es un tipo de norma que resulta aplicable a todos los miembros de la comunidad política ahora en cuanto ciudadanos y no ya en cuanto miembros de otros grupos sujetos a códigos particulares: atañe a patrones públicos o interpersonales de 
Cuadernos Electrónicos de Filosofía del Derecho

comportamiento erga omnes. Ciudadano es, precisamente, quien está sujeto a tales patrones ("aquellos que son naturalmente capaces de obedecer la ley”, 1134b13). Y la justicia política es la que opera entre iguales "según ley" (1134b13-14). La justicia es, por otro lado, virtud pros heteron: o sea, la única virtud que se refiere al bien de otro, esto es, al otro como ciudadano, en relación con el cual rigen las normas jurídicas del Estado y no sólo ya las normas morales o mores tradicionales. Y se trata del bien porque estas normas —además de proponerse el logro eficaz de fines técnicos de diferente naturaleza referentes a la organización social de la ciudad, comercio, defensa militar, etc.— están esencialmente orientadas hacia determinados fines últimos o valores: aquellos que figuran en la constitución política como los que justifican en última instancia la existencia y permanencia misma del Estado. La polis aristotélica no consiste en un "convivir" hobbesiano sino en un “vivir bien” (eu zên) (Pol., III, 9, 1280a31-2): esto es, conforme a una determinada concepción del bien común articulada en su constitución política como fin supremo colectivo.

De ahí que las leyes de que Aristóteles nos habla incorporen ya (reflexivamente o en segundo grado: lo que también significa selectivamente) las virtudes morales: "Pues la mayoría de las acciones impuestas por las leyes son aquellas que están prescritas desde el punto de vista de la virtud como un todo. En efecto, la ley ordena vivir conforme a todas las virtudes y prohíbe vivir según todos los vicios (Ét. Nic., V, 2, 1130b2225). Idea que no debe entenderse, entonces, meramente en un sentido perfeccionista moral, sino como expresiva de aquel proceso de construcción del orden jurídico-político por el cual ciertas conductas pasan a ser tipificadas por el derecho en cuanto que promueven o lesionan propósitos y bienes colectivos que las hacen valiosas o disvaliosas para cualquier ciudadano (pensemos, p. ej., en el paso del insulto como daño moral a la injuria como lesión de un bien jurídico protegible para todos - el honor-al margen de particulares concepciones morales). Por eso la justicia es la virtud total (holē aretēe), la suma de todas las virtudes. Visto desde el derecho, este proceso significa que la ley es justa en la medida en que incorpora justificaciones morales. Este es el lado moral del puente. Pero por otro lado está el lado político, en el que Aristóteles deja claro que las leyes se enderezan al bien común, no a la realización de una moral particular, y ello implica entre otras cosas tener que conciliar concepciones morales y valores divergentes en la constitución política (en una suerte de "consenso entrecruzado", diríamos hoy). De esta síntesis resulta que pueden existir leyes injustas en el sentido de contener normas moralmente injustificadas bajo el punto de vista 
Cuadernos Electrónicos de Filosofía del Derecho

de alguna concepción u opinión particular $y$, sin embargo, considerarse correctas desde el punto de vista del bien común (que Aristóteles enfatiza es más importante que el bien particular y garante de éste). Lo que no podría darse es leyes contrarias a los valores últimos constitucionales como fines últimos, pues "las leyes se hacen, y deben hacerse, según la constitución, y no la constitución según las leyes" (Pol., IV, 1, 1289a13-15).

\section{Ad ii) Justicia e igualdad. Tres dimensiones de la igualdad}

En cualquier caso, la función primaria de la legislación, para Aristóteles, es la generación de hábitos o cursos de acción virtuosos en los ciudadanos: "hacer a éstos buenos haciéndoles adquirir ciertos hábitos". Es, pues, una práctica de segundo grado: un "hacer hacer", y de nuevo la idea del valor (del bien) emerge, pues cuando el legislador no satisface ese designio - conformar desde ciertos valores las prácticas ciudadanasentonces "yerra el blanco, siendo en esto como se distingue la constitución buena de la mala" (Ét. Nic., V, 2, 1103b3-6). De modo que la legislación aparece como una suerte de condición de posibilidad, no ya del bien político, sino de la propia moralidad, sin quedar por ello recluida en la esfera moral (sino en el más amplio espacio de la moralidad política): "sólo a través de las leyes (dia nomon) podemos hacernos buenos" (X, 9, 1180b25-6). De hecho, la Ética nicomáquea va dirigida a los legisladores como interlocutores, $\mathrm{y}$ su último capítulo aborda expresamente esta transición de la moral a la política operada por las leyes. Transición que, como ya hemos visto, implica la emergencia de nuevos valores: el fundamental de ellos es el valor de la igualdad: pues la comunidad política, regida por la ley, es una comunidad "de libres e iguales" (V, 6, 1134a27-28), mientras que en las comunidades pre- o infraestatales rigen más bien relaciones de desigualdad. Esto nos lleva al segundo componente de la definición de la justicia: lo igual (to ison). ¿Cómo se relaciona la legalidad con el valor de la igualdad?

La igualdad es el constituyente primordial de la justicia. La fórmula común es de origen aristotélico: la justicia es tratar lo igual de modo igual y lo desigual de modo desigual. Se trata de un valor de segundo orden, formal, en tanto es una relación entre relaciones, un término medio entre desigualdades (lo más y lo menos, la ganancia y la pérdida) orientado a deshacer el desequilibrio injusto o pleonexia que éstas significan. En tal sentido presupone valores materiales de primer orden: los parámetros de la igualdad, tanto en el reparto (los merecimientos o axia) como en la reparación (la mensuración del daño o ilícito). Pero, dejando a un lado este difícil punto del lugar de la igualdad en las dos especies 
Cuadernos Electrónicos de Filosofía del Derecho

de justicia distributiva y correctiva, lo que nos interesa ahora es qué conexión media entre la justicia como igualdad y la legalidad. Esta conexión puede ser analizada a través de tres aspectos o dimensiones de la igualdad, que vamos a identificar con los siguientes tres términos: a) generalidad, b) justificabilidad, y c) regularidad.

a) Los legisladores sólo pueden cumplir con esa su función de generalizar hábitos entre los ciudadanos mediante el establecimiento de estándares de comportamiento válidos para todos. Ello exige que las leyes estén construidas según criterios de universalidad lógica, es decir, enclasando individuos, acciones, ocasiones espacio-temporales que puedan ser cuantificados (totalizados: "para todo $\mathrm{x}$ que cumpla las propiedades y, z, q...") y ulteriormente predicados de los casos o situaciones particulares por medio de variables de individuo (la llamada subsunción: “a es un x"). El nomos, enfatiza Aristóteles, habla universalmente: se refiere a tipos de acción, la decisión del legislador no es particular sino "prospectiva y universal [katholou]" (Retórica, I, 1, 1354b6-7). La legislación se construye a base de reglas o normas generales y abstractas, diríamos hoy. Eso implica al menos dos cosas: que las leyes sean públicas o escritas, y que sean taxativas, es decir, referidas en sus antecedentes y consecuentes a acciones definidas con claridad suficiente como para hacer posible una aplicación igualmente pública y argumentada en términos de relevancia y no de discreción. El filósofo está dirigiendo aquí una clara crítica al sistema jurídico de su tiempo, que manifiestamente no cumplía con ambas notas, y especialmente con la segunda de ellas, como se demostró en el juicio de Sócrates $^{6}$. De ahí la vinculación ineludible entre el nomos y el lenguaje, el logos que contiene representaciones universales (i.e., conceptos) y permite la planificación racional de la acción más allá de las meras representaciones particulares ligadas a la percepción y a los estímulos placerdolor (únicos que mueven a los animales) y supera también la indeterminación de las virtudes y los estereotipos morales. Así, explica Aristóteles: "cada una de las cosas justas y legales [dikaion kai nomimon] se relacionan como lo universal con los particulares, pues las cosas que se hacen son muchas, pero cada una de ellas es una, ya que es universal" (Ét. Nic., $\mathrm{V}, 7,1135 \mathrm{a} 5-8)$.

De manera que la práctica de legislar, de producir leyes, queda racionalmente definida como formulación de normas estrictamente generales y abstractas -no particulares y concretas - en su formato lógico, aun cuando esas leyes sean vistas también como el resultado de un razonamiento eminentemente práctico,

\footnotetext{
${ }^{6}$ Cf. A. LANNI, Law and Justice in the Courts of Classical Athens, New York, Cambridge University Press, 2006, pp. 59ss.,128, 189.
} 
Cuadernos Electrónicos de Filosofía del Derecho

decisorio (y, por tanto, particular). Ello es una exigencia de la justicia como igualdad: sólo de ese modo, sin hacer acepción de individuo, sino ecualizando las relaciones sociales según clases "abiertas", es posible "tratar lo igual de forma igual", la isonomía o igualdad ante la ley o igualdad de trato (que era un motivo de orgullo político para los griegos frente a los bárbaros: recuérdese el elogio fúnebre de Pericles). La generalidad es pues condición necesaria de la justicia. Y Aristóteles basa aquí su pionera defensa del "imperio de la ley", cifrada en el famoso aserto de que al margen de la ley, del nomos, no existe propiamente régimen político o politeia: "Donde no imperan las leyes no hay constitución" (Pol., IV, 4, 1292a32; cf. II, 9, 1269a32; III, 16, 1287a25ss.). La racionalidad de la política misma queda vinculada así al racionalismo normativo de las leyes. El gobierno de las leyes lo es de la razón (no de las pasiones: es razón sin pasión, sin elemento animal: III, 16, 1287a28-33) precisamente porque opera en términos lógicos, universalizadores, clasificadores, impersonales. El Estado y las relaciones gobernantesgobernados que se dan en su seno exigen una ordenación racional con arreglo a reglas generales, no exclusivamente a normas particulares: aquí Aristóteles establece un contraste decisivo entre el nomos y aquellas normas que no suponen justamente una deliberación de carácter universal (decretos y edictos) y que no pueden suplantar a las leyes so pena de generar regímenes desviados, es decir, irracionales. Los poderes políticos en suma están organizados de acuerdo con la primacía del poder legislativo (o deliberativo): "La ley debe ser suprema sobre todas las materias y los magistrados [las magistraturas, no sólo jurisdiccionales sino ejecutivas] deben juzgar solamente de los casos particulares: y únicamente así cabe decir que existe constitución" (IV, 4, 1292a32ss.).

b) Ahora bien, la generalidad de la ley es sólo una propiedad formal. Es precisamente lo que Weber llamó unos cuantos siglos después la "racionalidad formal" típica del Estado moderno y que a menudo, en contextos jurídicos, se identifica con la "justicia formal" o el formalismo en sentido positivo. La generalidad tiene carácter instrumental: es una condición necesaria para lograr la justicia pero no una condición suficiente ni un fin en sí misma. Por el contrario, similarmente al valor de la coherencia, el valor de la generalidad va ligado a los valores materiales, sustantivos, que integran aquella concepción del bien común que los legisladores pretenden poner en práctica mediante la forma lógica general de las leyes. Tales valores sustantivos son los verdaderos parámetros de la igualdad, aquellos desde cuyo 
Cuadernos Electrónicos de Filosofía del Derecho

punto de vista aflora propiamente recordemos - la justicia (y la injusticia) como realidad práctica. Y aquí Aristóteles reconoce abiertamente el problema de la diversidad de concepciones políticas de la justicia, la diversidad del bien político: la discusión sobre la justicia y la igualdad es la discusión sobre la constitución, sobre sus valores y principios sustantivos, que son aquellos que subyacen a las leyes ${ }^{7}$. A esta acepción sustantiva de la igualdad podemos llamarla igualdad como justificabilidad material, dado que los valores en cuestión son los que proporcionan la justificación última de las leyes $\mathrm{y}$, en una perspectiva pragmática, no idealista, tienen que ver íntimamente con lo que hoy llamamos igualdad material (igualdad efectiva o igualdad en los resultados). De ahí que Aristóteles funde la clasificación de los regímenes políticos en tales valores materiales y no en el mero dato formal de la existencia de leyes generales (lo cual nivelaría todos los regímenes como Estados de derecho). Es justamente ese criterio sustantivo el que determina su ordenación normativa de los regímenes en correctos y

\footnotetext{
7 “Todos están de acuerdo, en efecto, en que lo justo en las distribuciones tiene que estar de acuerdo con algún tipo de mérito. Sin embargo, no todos llaman 'mérito' a lo mismo: pues los partidarios de la democracia lo sitúan en la libertad, los de la oligarquía en la riqueza o, algunos de ellos, en la nobleza de estirpe, mientras que para los partidarios de la aristocracia estriba en la virtud" (Ét. Nic., V, 3, 1131a25-29, trad. propia)
}

desviados. Si estos últimos son aquellos donde los edictos y los decretos sustituyen a las leyes eso significa que es el bien particular de una facción o grupo (es decir, normas particulares) y no el bien colectivo de toda la comunidad lo que está siendo realmente perseguido. En cambio, en el régimen ideal, una politeia o democracia en la que "todas las personas toman parte en el gobierno por igual y en la mayor medida posible", el gobierno de las leyes estaría realizado del modo más pleno siempre que no degenere en demagogia ("donde el pueblo [la asamblea] y no la ley detenta el poder supremo y los decretos poseen supremacía sobre las leyes", comportándose así como los edictos del tirano: Pol., IV, 4, 1292a6-18), lo que se sólo consigue si prevalece una constitución en donde las leyes atiendan realmente al "interés de todos y cada uno" sometiéndose a los valores de la virtud moral y la libertad (lo que hoy llamaríamos una constitución rígida dotada de un catálogo de derechos).

c) Por último, el tercer sentido de la igualdad concierne al proceso y a los medios que hacen posible la consecución de los dos tipos anteriores de igualdad. Es decir, que producen de hecho la generalización de reglas de conducta y la implantación efectiva de los valores subyacentes a éstas en el seno de las relaciones sociales. Ambas cosas serían inviables sin añadir a la instancia de producción 


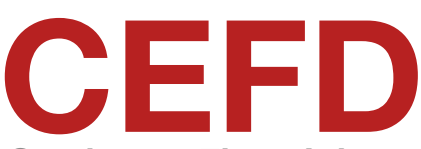

Cuadernos Electrónicos de Filosofía del Derecho

de reglas (la legislación), una instancia de aplicación intermediaria entre la práctica del legislador y las prácticas sociales que haga a aquéllas eficaces en éstas: esa es la función judicial. El juez es, según Aristóteles, "guardián” y "personificación” de la justicia “y, si de la justicia, también de la igualdad" (Ét. Nic., V, 4, 1132a21-22; 6, 1134b1-2). Su función es asegurarse de que se verifican en la práctica de manera constante, continuada y recurrente las reglas de acción emanadas de la legislación política y a través de ellas los valores de igualdad material (distributiva y conmutativa) y de libertad que la ley pretende fomentar generalizadamente en las relaciones sociales. Recordemos que la justicia es la virtud que tiene que ver con la práctica recursiva de las cosas justas: usando un término técnico de la filosofía aristotélica, es una energeia o "actualización" constante de los valores de justicia. No es suficiente con legislar para implantar socialmente tales valores, no sería posible (o no lograría la justicia política) un orden jurídico exclusivamente basado en la legislación: es preciso que exista además una jurisdicción que ponga en práctica, mediante una secuencia de decisiones singulares imparciales en aplicación de la misma, las reglas que contiene. Eso es lo que significa que "impera" la ley, que se impone su autoridad (kurios). Y por eso podemos hablar de regularidad o recurrencia para referirnos a esta dimensión de la igualdad involucrada en el proceso práctico de aplicación de la ley ${ }^{8}$.

\section{Ad iii) La continuidad entre legislación y} jurisdicción

Sentada la necesidad de la legislación como institución jurídica central — la necesidad de las leyes, su génesis, su función, su estructura lógica-, Aristóteles asume que ésta se da, como vemos, en continuidad práctica con la jurisdicción. La originalidad del enfoque aristotélico reside en haber visto que este continuum no sólo impide establecer cortes abruptos o dicotómicos entre ambas instituciones (por ejemplo: entre "creación” y "aplicación" del derecho) sino que además cada una de ellas debe verse "dualmente": ambas prácticas están reflejando, en su estructura interna, las pautas de racionalidad de la otra. Así como el legislador no puede llevar adelante su labor normadora si no toma en cuenta una instancia aplicativa desarrollada deferida y autónomamente por otros sujetos, los jueces, cuya perspectiva racional ha de asumir (y reglamentar), así tampoco éstos

\footnotetext{
${ }^{8}$ Por supuesto, la aplicación judicial de la ley no excluye la aplicación e implementación de la misma que es propia de las agencias ejecutivas y administrativas, actuantes mediante normas particulares y decisiones políticas singulares. Al revés, la presupone y tiene respecto de ella una función fiscalizadora como último pronunciamiento autoritativo institucional dentro del derecho acerca del alcance, significado y legitimidad de la legalidad del resto de normas (o de la constitucionalidad de la propia ley, si hablamos del tribunal constitucional).
} 
Cuadernos Electrónicos de Filosofía del Derecho

pueden llevar a cabo su función aplicadora sin justificar sus decisiones sobre la base de reglas formales preexistentes, lo que conlleva reconstruir la racionalidad y sentido de éstas desde el punto de vista del legislador como autoridad política. La teoría aristotélica de la equidad no es sino la explicitación de esta "dualidad" desde la perspectiva del juez.

En diversos pasajes de la Ética y la Retórica, algunos de los cuales ya hemos citado, contrasta Aristóteles la deliberación legislativa y la deliberación judicial (siendo ambas especies de prudencia $\mathrm{o}$ de razonamiento práctico $\mathrm{y}$ formando, como decimos, un continuo). La primera es especialmente prolongada, se encamina al logro de ciertos valores a la escala de la comunidad política (la concepción del bien colectivo plasmada en la constitución), es “arquitectónica", es prospectiva u orientada al futuro, al regular tramos de conducta mediante normas, y consiste en la formulación de reglas generales, universales, esto es, desemboca en una única decisión pero relativa a todos los casos de un cierto tipo. La segunda, en cambio, es una deliberación mucho más localizada, que se centra en un caso, en este caso, en cada uno de los casos particulares en que resulta pertinente la regla legislativa, casos que son presentados a ellos de manera "imprevista", a través de las disputas y conflictos sociales en que se demanda una solución por parte del derecho, de la ley ("casos presentes y determinados", Ret., I, 1, 1354b4ss.), y que tiene un carácter retrospectivo, tanto en relación con los hechos y circunstancias del caso, que es un suceso pretérito, como en relación con los criterios para su valoración, que están predeterminados en la ley: lo que se trata en el juicio es de reconstruir esos hechos -los conflictos subyacentes - para establecer cuál es la respuesta correcta según la ley.

Cómo se conecta la deliberación judicial con la deliberación legislativa: ese es el problema fundamental al que trata de responder la teoría de la equidad. En cierto sentido, se trata del problema general de la racionalidad de la práctica de seguimiento de reglas, que Wittgenstein planteó en términos pragmáticos muy similares. Este problema se formula de manera específica en el campo jurídico como el de la "metodología jurídica": qué tipo de racionalidad está implicada en la aplicación e interpretación de las reglas jurídicas (p. ej.: cómo debe reconstruirse el sentido de una norma, cuál es su relación con las razones subyacentes o principios, etc.). Pero, en realidad, el problema no es sólo "metodológico" o “técnico", sino también político-moral. Afecta, de un lado, al diseño institucional del Estado: la organización de autoridades y distribución de poderes dentro de éste. Y de otro, y sobre todo, afecta al entendimiento mismo de la justicia política, al poner en juego los valores 
Cuadernos Electrónicos de Filosofía del Derecho

fundamentales que han de regir en una comunidad política y el modo como se traducen en decisiones concretas. El problema podría formularse así: asumiendo que la organización política de la justicia exige el establecimiento de estándares de conducta generales, universales (el nomos), y asumiendo que la institución judicial, bajo un sistema de gobierno de las leyes, está regida centralmente por el deber de aplicar $\mathrm{y}$ hacer cumplir esos estándares legislativos, como medio necesario para que los valores fundamentales que se consagran en la constitución se mantengan vigentes en las prácticas sociales; asumiendo, por tanto, que el juez ha de individualizar los enunciados universales establecidos por el legislador respecto de cada una de las situaciones particulares a ellos planteadas, ¿de qué modo se ajustan los casos particulares a tales estándares generales y los valores que portan y de qué modo — a la inversa- son éstos determinados en su significado y alcance general al verse concretados para cada una de las situaciones particulares?

La respuesta aristotélica a este problema arranca de su concepción de la razón práctica, de la que el propio derecho sería una suerte de plasmación institucional, habida cuenta de que su racionalidad está enteramente formalizada y estructurada en referencia a reglas prácticas. Se basa en la tesis fundamental de que la aplicación judicial de tales reglas del derecho no puede verificarse en términos de simple consistencia lógica (a partir de la formulación de las reglas: de su generalidad), sino que requiere además un juicio de coherencia o congruencia axiológica con los valores que justifican esas reglas (justificabilidad). Dicho de otro modo: que el deber del juez - un deber que rige su racionalidad práctica - a la hora de aplicar la ley incluye también el deber de corregirla recurrentemente a la luz de sus valores subyacentes siempre que su generalidad sea un obstáculo para, o suponga una frustración de, su justificabilidad en un caso particular. Veamos el profundo alcance de esta tesis.

\section{Doce tesis antiformalistas derivadas de la equidad aristotélica}

La tesis de la equidad, así formulada, sienta una crítica destructiva de todo género de formalismo jurídico. Cabe sintetizar los múltiples frentes de esa crítica, que van - como vimosdesde la concepción general del derecho a las pautas de la aplicación judicial pasando por el diseño del Estado de derecho, en los doce puntos que siguen:

i) Una comprensión adecuada -no formalista - del Derecho dista de poder restringirse a sus reglas: ha de ampliarse, por el contrario, a los principios y valores que subyacen a ellas dotándolas de sentido y justificación. Allí donde existan reglas legisladas existirán también 
Cuadernos Electrónicos de Filosofía del Derecho

principios (implícitos o explícitos) que reflejen tales valores. Tales principios determinan enteramente la estructura del derecho y del "método" jurídico. Si los valores preexisten a las reglas y son su razón de ser, la racionalidad práctica en relación con reglas ha de movilizar necesariamente a ambos, de forma que una regla puede imponerse exclusivamente en la medida en que esté justificada por relación a esos valores o principios sustantivos.

ii) En relación con la legislación misma, la tesis de la equidad comporta la crítica radical del "legalismo". Esta sería una concepción que equivoca profundamente la epistemología que está en el trasfondo de la noción de "ley" operante en el derecho. La idea de ley se aplica a la praxis por analogía con las regularidades objetivas necesarias de la physis construidas por la episteme (la "analogía epistémica" antes mencionada), e implica, como dijimos, la pretensión de racionalizar las acciones humanas en términos de normas o reglas bajo categorías lógicas y en términos de universalidad. Pero esta metáfora racionalista - la idea de una "regla universal" que determina la acción-, tan decisiva en la historia de la filosofía práctica, no puede ser tomada como si expresara una identidad y no precisamente una analogía. Es decir, como si las relaciones de tipo lógico, y no las de orden valorativo, fueran las que ordenan realmente el mundo práctico: en este caso, una empresa práctica de carácter político-moral como es la del legislador. Así, por ejemplo, el legalismo da por cierta la posibilidad de lo que Kant llamaba "ley estricta" 9: es decir, la "regla perfecta" (Günther) capaz de garantizar por anticipado la corrección de todas sus aplicaciones futuras en los casos particulares ${ }^{10}$; una regla que no requiere excepción alguna y que por tanto excluye la necesidad de un discurso de aplicación deliberativo y justificativo autónomo comprometido valorativamente. Esta visión se convirtió en dominante a lo largo de toda la ideología jurídica moderna, tras las codificaciones positivistas y el modelo de Estado de derecho liberal subsiguiente, pero sigue muy presente en la concepciones actuales de las "reglas" del derecho incluso entre los representantes del postpositivismo y el constitucionalismo (que siguen viendo en buena medida las reglas como dispositivos de aplicación cerrada, binarios todoo-nada, vinculados a una operación de "subsunción” esencialmente lógica, que suprimen o "ahorran" la deliberación...). Una enseñanza principal del modelo de gobierno de las leyes aristotélico es que los valores que promueve la legislación no pueden ser conseguidos ni

\footnotetext{
${ }^{9}$ I. KANT, Sobre la paz perpetua, trad. J. Abellán, Madrid, Tecnos, 1998, pp. 12-3, n.

${ }^{10}$ K. GÜNTHER, "Un concepto normativo de coherencia para una teoría de la argumentación jurídica", Doxa, 1995/17-18: 271-302, p. 279.
} 
Cuadernos Electrónicos de Filosofía del Derecho

solamente mediante reglas — los valores formales asociados a éstas no son garantes por sí mismos de los valores sustantivos- ni solamente mediante un sistema rígido de aplicación de reglas mediante mecanismos supuestamente lógicos. Esto nos lleva al siguiente punto.

iii) Ya específicamente respecto de la jurisdicción, la tesis de la equidad supone que la práctica aplicativa judicial no puede ser tampoco reducida a la imagen (especular respecto de la regla perfecta legalista) de un "silogismo" consistente en la simple "subsunción" o "clasificación" lógico-formal de casos bajo las cláusulas genéricas legislativas. La aplicación de las leyes - la jurisprudencia- es una empresa normativa e interna al derecho. Es decir, posee un carácter necesariamente deliberativo y creador que conforma la legislación a lo largo del proceso de su aplicación al compás del desarrollo de las prácticas sociales (es, por tanto, también una práctica de segundo grado, como la legislativa) y que necesariamente conduce a la producción de nuevas reglas. En este punto tanto las interpretaciones positivistas como iusnaturalistas han incurrido en el mismo error de contraponer antitéticamente legalidad y equidad (compartiendo paradójicamente idénticos presupuestos formalistas o legalistas): ambas ubican la equidad fuera del Derecho; los primeros para considerarla algo a prohibir por ser el ámbito de la discrecionalidad que va más allá del derecho legislado (el "funesto arbitrio de los jueces", de Filangieri; la "discrecionalidad fuerte" del iuspositivismo contemporáneo), y los segundos para considerarla vehículo de valores absolutos fundamentalmente extrajurídicos (el "derecho natural", la "moral"), de los cuales el derecho es mero soporte formal contingente. La tesis de Aristóteles en cambio (en perfecta consonancia con las orientaciones post-positivistas actuales) es que la equidad es interna al derecho en cuanto institución práctica: la equidad va más allá de las reglas pero no del derecho, pues se refiere a los principios y éstos también forman parte del derecho (por más que reflejen valores objetivos externos). La equidad no niega las reglas, sino su entendimiento exclusivamente formalista $\mathrm{o}$ literalista. Éstas no son "formas vacías" en ninguno de ambos sentidos: ni obedecen solamente a valores formales (como la seguridad jurídica), ni son mera “deducción” o reflejo de principios sustantivos o de justicia material. Los valores de justicia son formalizados por el derecho a través de reglas como parte de un proceso político más amplio y complejo en el que participan tanto legisladores como jueces.

iv) La equidad como corrección de la ley parte de una comprensión pragmática de las reglas legislativas, una vez que el propio razonamiento del legislador (del cual resultan las generalizaciones de predicados fácticos $\mathrm{y}$ 


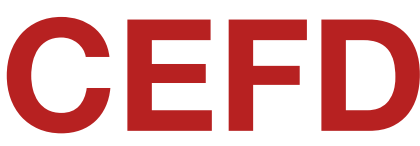

Cuadernos Electrónicos de Filosofía del Derecho

normativos de que constan las reglas) se revela como un razonamiento práctico originariamente dirigido por valores, propósitos y fines que el juez tiene que poder identificar para emprender su propio discurso de aplicación. La indeterminación o "textura abierta" de las reglas jurídicas, por usar la expresión que Hart hizo famosa, arranca del carácter necesariamente evaluativo, no natural, de los conceptos incorporados a ellas en cuanto conceptos prácticos o relativos a la constelación de la acción humana (o incluso, aunque sean conceptos naturales, en cuanto pasan a formar parte de una empresa de índole decisoria). La dificultad intrínseca que Aristóteles encuentra en formular un "juicio universal que sea correcto" (Constitución de los atenienses, 9) arranca de este hecho: pues que sea universal, tratándose de un juicio prospectivo de carácter práctico, implica que sus implicaciones para el futuro son precisamente valorativas y que, por lo tanto, el juicio retrospectivo del aplicador ha de producirse forzosamente en términos de congruencia o coherencia pragmática $^{11}$. De manera que la identificación de las condiciones de aplicación de las reglas requiere siempre de juicios de valor en primera persona a cargo del juzgador que no

11 Como señala Aguiló, "la universalidad presupone el compromiso de resolver del mismo modo todos los casos iguales" (AGUILÓ, J., "Fuentes del Derecho", en Enciclopedia de Filosofía y Teoría del Derecho, México, UNAM, 2014, vol. 2 (pp. 1-53), pp. 37-38). están (ni pueden estar) contenidos en las propias reglas, sino que exigen una deliberación creativa específica, en términos de las razones o principios que las fundamentan ${ }^{12}$. La equidad de Aristóteles anticipa la intuición central de la hermenéutica jurídica según la cual la interpretación es un proceso que transforma las normas interpretadas e implica un mejor conocimiento de ellas que el que pudo tener su propio autor. La razón de ello es que el legislador no puede conocer todas las consecuencias de sus normas (la "relativa indeterminación de los propósitos" de que hablaba Hart, que ninguna técnica legislativa puede remediar) mientras que el intérprete tiene una perspectiva retrospectiva que al partir del caso está obligada a someterlo a una nueva valoración (un "fresh judgment”, decía Hart). La causa última de la indeterminación de las reglas no estriba, pues, en la ley general ni en el legislador sino en la "naturaleza de la práctica", es decir, en el hecho de que las situaciones prácticas en las que tales reglas han de ser aplicadas son siempre nuevas y cambiantes. Las reglas son desbordadas constantemente por las prácticas sociales, debiendo sin embargo éstas ser, también constantemente, uniformizadas y estandarizadas bajo ellas en términos coherentes por las prácticas aplicativas. La corriente de la

12 Cf. C. NINO, La validez del derecho [1985], Buenos Aires: Astrea, 2006, pp. 52ss.; R. DWORKIN, Law's Empire, Harvard, Belknap Press, 1986, pp. 66ss. 
Cuadernos Electrónicos de Filosofía del Derecho

práctica social, sobre la cual las reglas son proyectadas, es comparable al río de Heráclito: ninguna regla puede ser mecánicamente aplicada a ella del mismo modo, porque el hecho mismo de la aplicación supone que ni será ya la misma regla ni la misma situación. Lo único que garantiza la "identidad de propósitos" con la legislación es la iteración recursiva de las mismas razones: que los principios o valores implicados se reflejen del mismo modo en la resolución de cada caso (lo que exigirá muchas veces decisiones distintas: eso es lo que capta la metáfora de la regla de plomo). Bajo esta perspectiva pragmática, las diferencias de orden justificativo entre un sistema de legislación y un sistema de precedente tienden a minimizarse.

v) El juez debe comprobar en cada caso la correcta aplicabilidad - esto es, la justificabilidad - de la regla relevante desde el punto de vista de sus principios subyacentes: es decir, debe verificar que su aplicación al caso, a la vista de las circunstancias, no contravenga o defraude los balances de valores o razones que mediante esa regla el legislador está tratando de promover. Es un prejuicio formalista dar por hecho que la coherencia está asegurada por el automatismo de las solas reglas sin necesidad de una actividad argumentativa que afecte a su “justificación externa". vi) Por lo tanto, el primado metodológico de la interpretación literal (en tanto instrumento básico para salvaguardar los valores de un Estado de derecho que otorgue centralidad al poder legislativo democrático) no puede ser visto como un recurso aplicativo que opere con independencia de juicios de valor, un procedimiento "algorrítmico" de formato “objetivamente subsuntivo" o "lógico" (la "vía de carriles infinitamente largos" que criticaba Wittgenstein). Por el contrario, la operación de clasificación o calificación mediante la que se establece la relevancia de una regla para un caso incluye necesariamente un elemento deliberativo de evaluación de las circunstancias del caso y de la corrección de la regla en relación con el mismo en donde necesariamente intervienen las razones subyacentes (los principios o valores). De manera que los llamados "casos fáciles" (aquellos en los que opera ordinariamente el "imperio de la ley" y que a veces se da por descontado que serían la mayoría) lo son no tanto porque en ellos se pueda prescindir de tal deliberación evaluativa cuanto precisamente porque en ellos las ponderaciones de valores y balances de principios relevantes se ven salvaguardados y se preserva así la continuidad axiológica con los propósitos del legislador. En este punto es formalista toda tesis que afirme que tal continuidad puede mantenerse al margen de la adhesión y la complicidad argumentativas del aplicador (p. ej., entendiendo 


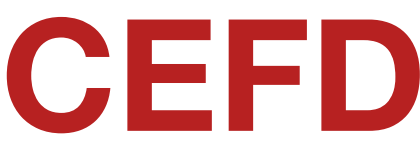

Cuadernos Electrónicos de Filosofía del Derecho

que las reglas son instrucciones perentorias $\mathrm{o}$ excluyentes) y como una mera cuestión "de hecho" desprovista de interpretaciones de valor ${ }^{13}$.

vii) Si los casos "fáciles” lo son por razón de su justificación sustantiva, los llamados casos "difíciles" lo son - a fortiori- porque exigen corregir las reglas relevantes aplicables introduciendo excepciones por parte del juez a fin de evitar consecuencias injustificadas. Ello sucede básicamente de dos maneras o, mejor, en dos niveles relativamente diferenciados. En primer lugar, tenemos los casos que Schauer llama de suprainclusión e infrainclusión, en donde la generalización de la regla contradice (sea porque va más allá o más acá) ${ }^{14}$ aquello que su razón subyacente está justificando. Por ejemplo: una ley prohíbe que los menores de edad donen órganos para trasplantes (bajo la razón de proteger su integridad y salud, evitar abusos, etc.) y se da el caso de una madre menor (incluso rozando la mayoría de edad) cuyo hijo sufre una enfermedad gravísima que le producirá la muerte a menos que

\footnotetext{
${ }^{13}$ Por ejemplo, la tesis de que la identificación del derecho depende "exclusivamente de hechos de conducta humana susceptibles de ser descritos en términos valorativamente neutrales y aplicados sin recurso a una argumentación moral" (J. RAZ, The Authority of Law. Essays on Law and Morality [1979], New York: Oxford UP, 1983, pp. 39-40).

${ }^{14}$ F. SCHAUER, Playing by the Rules [1991], New York, Oxford UP, 2002, p. 39. Los "casos recalcitrantes" son una forma diferente de llamar a los desajustes reconocidos desde antiguo en la tradición jurídica entre la letra de la ley y la intención del legislador (plus dixit quam voluit y minus dixit quam voluit).
}

sea trasplantado de su propia madre como donante. La prohibición, que está obviamente justificada en general, ha de dejar de estarlo en este caso particular (la protección del valor de la vida humana y la inexistencia de riesgo en él exigen introducir una excepción). El propio Aristóteles invoca en un célebre fragmento de la Retórica un ejemplo similar ${ }^{15}$. La justificabilidad de la regla exige que sea corregida en casos como estos las consecuencias derivadas de la generalidad de su formulación. La razón es la señalada por Aristóteles: "porque el propio legislador la habría corregido si hubiera conocido el caso"; es decir, porque de otro modo quedaría comprometida la congruencia axiológica con los propósitos objetivos que justifican la decisión del legislador, que es lo único que le otorga legitimidad. Si cabe hablar de excepciones (y si éstas son exigibles al juez en su desempeño

15 "En efecto, la equidad parece que es justa, pero es un tipo de justicia que va más allá de la ley escrita. Ello sucede una veces por propia intención del legislador y otras veces por inadvertencia suya. Sucede intencionalmente cuando el legislador no puede tipificar o definir las acciones con precisión y, sin embargo, es necesario que se pronuncie en términos universales, remitiéndose en su ley así solamente a lo que sucede con mayor frecuencia. En muchos casos la práctica no es fácil de definir a causa de su indeterminación. Por ejemplo: ¿cuántas clases de armas y de qué tamaño deben considerarse para definir el delito de herir a otro? Toda una vida no sería tiempo bastante para enumerar todas las posibilidades. Por tanto, si las acciones son imposibles de definir con total precisión y, sin embargo, es necesario establecer una ley, ésta no tiene más remedio que hablar en términos generales. Y así, en el mismo ejemplo, alguien que llevara un anillo y, al levantar su mano, golpeara a otro, habría cometido el delito de herir con arma desde el punto de vista de la literalidad de la ley, siendo así que, desde el punto de vista de la equidad, no es en realidad culpable de tal delito" (Ret., I, 13, 1374a27-1374b1, trad. propia). 
Cuadernos Electrónicos de Filosofía del Derecho

práctico-racional de aplicación de las reglas del derecho) es, pues, porque están justificadas: porque amplían o restringen el alcance de la regla manteniendo incólumes al mismo tiempo los balances de valores adoptados por el legislador (la “identidad de razón”) a lo largo del curso cambiante de la práctica social. Por eso afirma Aristóteles que la equidad es "la justicia que va más allá de la formulación escrita de la regla": no corrige en realidad la universalidad de la "regla" (la excepción viene a "confirmarla", como suele decirse) sino sólo su generalidad ("el error que resulta de su carácter absoluto"). Lo justo - lo racional - es tratar lo desigual de forma desigual y lo injusto — irracional — mantener la regla igual para estos casos relevantemente distintos. El formalismo aquí estribaría en ese remedo actual de las ideas codificacionistas napoleónicas (recordemos la conocida frase del general ante las primeras interpretaciones doctrinales: "Mon code est perdu") consistente en asumir como una seña de identidad del "método jurídico" o de la "racionalidad de reglas" la indemnidad a toda costa de las mismas en cuanto lógicamente generales $y$ en aceptar los costes de tal automatismo como "errores" o "efectos subóptimos" de menor cuantía ${ }^{16}$. Al asumir la generalización de estos costes o errores "colaterales", esta posición refleja una preferencia

\footnotetext{
${ }^{16}$ F. SCHAUER, F., Playing by the Rules, cit., pp. 131ss.
}

general por los valores instrumentales de orden formal o institucional (igualdad formal, seguridad jurídica, estabilidad) en detrimento de los valores intrínsecos de justicia material, mirando a veces además con desconfianza a los "principios" como normas jurídicas $\mathrm{y}$, por descontado, a las capacidades deliberativas de los jueces frente a las del legislador.

viii) Un segundo nivel más profundo en el que opera la corrección o "derrotabilidad" judicial de las reglas conduce a la creación de nuevas reglas y no ya sólo la introducción de excepciones a las reglas establecidas. Aunque la diferencia entre ambos casos - desde el punto de vista del aplicador - es más bien borrosa (pues toda excepción puede verse como una reformulación de una regla dada o el inicio de una nueva regla para todos los casos futuros similares al excepcional) lo importante es entender que ahora entra en juego una pluralidad de reglas $y$, por tanto, otros principios de orden superior que concurren con los subyacentes a la regla en cuestión. Hablamos, pues, de la justificación de las reglas legislativas desde la perspectiva del "sistema" del derecho considerado como un todo unitario al nivel de sus principios, todo unitario que el juez ha de proyectar sobre cada caso particular en el curso de su razonamiento decisorio $\mathrm{y}$, sobre todo, de su motivación $\mathrm{y}$ justificación, lo cual le obliga a volverlo coherente. Ahora lo que está en cuestión es el 


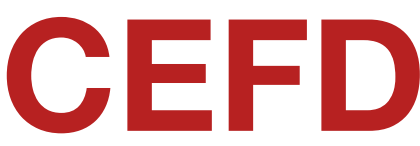

Cuadernos Electrónicos de Filosofía del Derecho

balance de principios mismo que se considera correcto como soporte de una cierta regla. O sea, no se corrige sólo el alcance de la regla respecto de un caso sino su misma validez y contenido normativo respecto de todos los $\operatorname{casos}^{17}$. Por tanto, el juez actúa ahora "como si fuera un legislador" en un sentido notoriamente más fuerte, puesto que introduce nuevas reglas, tal como recogió célebremente el artículo 1 del Código Civil suizo de $1907^{18}$, o — más claramente aún - revoca las propias reglas legisladas (tal como sucede con el control de constitucionalidad). En este orden de cosas la equidad aparece como un principio institucional que tiene que ver con la ponderación de valores en cuanto pauta metódica rectora de la racionalidad judicial. Este principio es muy visible ya en la interpretación ordinaria: en los procedimientos de resolución de lagunas $\mathrm{y}$ antinomias, que desarrollan el derecho objetivo generando reglas mediante razonamientos de principio en términos de analogía y demás argumentos hermenéuticos, por no hablar de los "ilícitos atípicos" (como el abuso de derecho o el

\footnotetext{
${ }^{17} \mathrm{O}$, en palabras de SCHAUER, no los "errores de la ley" sino los "errores del legislador" (o. cit, p. 154).

18 "Kann dem Gesetz keine Vorschrift entnommen werden, so soll das Gericht nach Gewohnheitsrecht und, wo auch ein solches fehlt, nach der Regel entscheiden, die es als Gesetzgeber aufstellen würde" (Art. 1.2 ZGB). Es significativo que el inspirador del código, Eugen Huber, pretendiera dar expresión en ese artículo al imperativo categórico kantiano.
}

fraude de ley) ${ }^{19}$. Son por tanto procedimientos que se fundan en consideraciones valorativas (y no sólo lógicas) ${ }^{20}$. Pero donde ello resulta innegable es en la interpretación constitucional, en la medida en que las constituciones normativas de los Estados constitucionales de derecho se caracterizan por formalizar ciertos valores en forma de principios que aspiran a determinar límites y condiciones a todas las demás normas jurídicas y en general a los actos de los poderes públicos (en especial a partir de un catálogo de derechos fundamentales $y$ de directrices políticas). El formalismo en este contexto se manifiesta en la suspicacia hacia la ponderación, como si las cuestiones problemáticas que suscita la labor interpretativa de los tribunales constitucionales (los conflictos entre derechos o valores, el deslinde entre cuestiones de legalidad ordinaria y cuestiones de constitucionalidad, etc.) pudieran ser resueltas siguiendo otro método que la interpretación "constructiva" a la luz de valores (por decirlo al modo de Dworkin). La tesis de la

19 ATIENZA, M. y RUIZ MANERO, J., Ilicitos atípicos. Sobre el abuso del derecho, el fraude de ley y la desviación de poder, Madrid, Trotta, 2000.

${ }^{20}$ En realidad, todo el conjunto de la actividad interpretativa judicial (no sólo los cánones de la interpretación de las leyes sino también la apreciación de los perfiles singulares del caso a efectos de calificación, relevancia y prueba) está construido a base de consideraciones valorativas. Ello queda reflejado en los criterios de la equidad que Aristóteles refiere: "Mirar no a la ley, sino al legislador; no a la letra, sino a la intención del legislador; no al hecho, sino a la intención; no a la parte, sino al todo; no cómo es ahora el acusado, sino cómo era siempre o la mayoría de las veces" (Ret., I, 13, 1374b11). 
Cuadernos Electrónicos de Filosofía del Derecho

equidad comporta que los juicios de valor no son el residuo del método jurídico sino su núcleo, y que la racionalidad de éste estriba no en neutralizarlos sino en sacarlos a la luz y justificarlos.

ix) La legitimidad del poder judicial es esencialmente argumentativa ${ }^{21}$. Como explica Aristóteles, el gobierno de las leyes es el gobierno de la razón ${ }^{22}$. Se trata, sin embargo, de una "razón práctica" que, en lo que respecta a los jueces, no puede ser diseñada (so pena de incurrir en ideología-deformante) como si fuera una razón "técnica" o "científica" de carácter "impersonal" en la que sólo contase la vinculación formalprocedimental a reglas como garantía de una "objetividad" procurada por presuntos mecanismos lógicos. Por el contrario, es una razón comprometida valorativamente a todos los efectos con los contenidos y consecuencias prácticas de tales reglas $\mathrm{y}$, por lo tanto, metodológica y políticamente responsable de ellas. La apelación formalista a las reglas sólo puede servir, en el mejor de los casos, para convalidar bajo apariencia de asepsia axiológica la imposición efectiva de juicios de valor no explicitados ni en sí mismos ni en la prioridad que

21 Cf. R. ALEXY, "Los derechos fundamentales en el Estado constitucional", en M. CARBONELL, Neoconstitucionalismo(s), Madrid, Trotta, 2003, pp. 31-47.

22 "No permitimos que nos mande un hombre sino la razón" (Ét. Nic., V, 6, 1134a35-6). reciben respecto de otros posibles. La mala comprensión de la dimensión "técnica" de la jurisdicción se aúna con la mala comprensión de su dimensión política (ideológica) en cuanto a la arquitectura de poderes que comporta un Estado de derecho. La tesis aristotélica es que el "imperio de la ley" (y por tanto la "vinculación del juez a la ley") no es idéntico al imperio del legislador. En efecto, es irracional pretender poner a resguardo la política democrática y la unidad de propósitos prácticos con el poder legislativo como poder rector mediante el expediente de introducir sospechas metódicas o ideológicas (incluso prohibiciones institucionales) en relación con las posibilidades de desarrollo jurisprudencial del derecho y de derrotabilidad de reglas por parte del poder judicial ordinario o del "contrapoder" legislativo ("contramayoritario") de la jurisdicción constitucional. El imperio de la ley es el imperio de los principios y valores políticomorales que se reflejan en la constitución: que son los fundamentos últimos que "cierran" el derecho como un sistema práctico de normas y la única fuente de autoridad de todos los poderes estatales. En el caso del poder judicial, si bien es claro que los jueces son "órganos de cierre" del derecho (más infalibles por últimos que últimos por infalibles, como sabemos), no lo es menos que los riesgos del "activismo judicial", del "gobierno de los jueces", del "funesto arbitrio" de la discrecionalidad judicial, de la "tiranía de los 


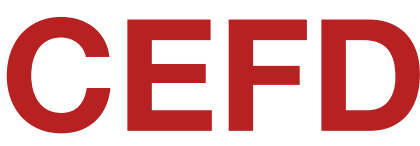

Cuadernos Electrónicos de Filosofía del Derecho

valores"... no pueden ser conjurados simplemente reiterando los deberes - las reglas - que disciplinan la práctica de la jurisdicción como autoridad o poder: aquí más que en ningún otro caso, dada la naturaleza racional-argumentativa de su función, debe enfatizarse que la dimensión justificativa del derecho no descansa sobre su dimensión autoritativa sino a la inversa, que son los valores que gravitan sobre la función judicial los que fundamentan y justifican sus deberes y que, por ello, será siempre más eficaz apelar a la responsabilidad y la auto-restricción interna que a cualquier sanción institucional externa. Debe ser superada, pues, la vieja ideología positivistaformalista del "poder nulo" del juez ${ }^{23}$. En todo

${ }^{23}$ Supervivencias claras de esa ideología jurídica pueden hallarse, por citar sólo algunos botones de muestra, en la tesis de SCHAUER de la "asimetría de la autoridad" (según la cual el juez sería susceptible de cometer mayor número de errores deliberativos, en términos agregados, que los legisladores, lo que justificaría por sí solo la existencia de un sistema de reglas como "mal menor" [o. cit., pp. 128ss.]; en la concepción "cognoscitiva" de la jurisdicción de Ferrajoli y su reducción de la equidad a simple "poder de connotación" o comprensión de las circunstancias del caso sin desbordar lo "denotado" por el legislador en la ley, o su tesis de que los principios constitucionales operan como reglas autoritativas que eluden toda ponderación (cf. L. FERRAJOLI, Derecho y razón [1989], Madrid, Trotta, 2000, pp. 156ss; "Constitucionalismo principialista y constitucionalismo garantista", Doxa, 34 (2011): 15-53); en la apuesta por las reglas en detrimento de los principios de Laporta (cf. F. J. LAPORTA, El imperio de la ley. Una visión actual, Madrid, Trotta, 2009, y J. RUIZ MANERO, "Las virtudes de las reglas y la necesidad de los principios. Algunas acotaciones a Francisco Laporta", en F.J. LAPORTA, J. RUIZ MANERO y M. A. RODILLA, Certeza y predecibilidad de las relaciones juridicas, Madrid, Fundación Coloquio Jurídico Europeo, 2009, pp. 95-123); en el desdén de García Amado hacia la ponderación como método exclusivamente enmascarador de caso, la práctica del derecho no termina con la práctica judicial: es un proceso complejo y no clausurado en el que los jueces, siendo órganos deliberativos, no tienen sin embargo la última palabra ni, desde luego, tienen asignada institucionalmente la función de la deliberación orientada al cambio de las normas: eso corresponde políticamente sólo el legislador, el cual - como el propio Aristóteles insinúatambién puede en todo caso actuar "como si fuera un juez", esto es, corrigiendo una línea jurisprudencial determinada (por ejemplo, si la tensión entre la deferencia al legislador democrático y el control constitucional, entre la propia constitución y su lectura por el tribunal constitucional, etc. superan ciertos umbrales). Resulta evidente que los juicios al respecto (así como los relativos a la legitimidad constitucional de una legislación particular) sólo pueden ser contextuales. No es una cuestión acerca de quién tiene la "última palabra", si se trata de un proceso abierto de deliberación pública.

x) El compromiso con valores otorga a la función judicial una inesquivable dimensión político-moral. La decisión justificada de los casos de acuerdo con una práctica regular que debe ser coherente (y, especialmente, coherente con los valores constitucionales que fijan la

las valoraciones del juez (cf. M. ATIENZA y J. A. GARCÍA AMADO, Un debate sobre la ponderación, Lima, Palestra, 2012). 


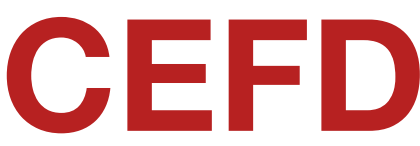

Cuadernos Electrónicos de Filosofía del Derecho

moralidad política de una comunidad) exige de los jueces la explicitación de doctrinas materiales comprehensivas e incluso - en el caso de los tribunales constitucionales - de concepciones de franco calado filosófico-político y moral $^{24}$, en el momento de fundamentar sus ponderaciones. Esta exigencia no sólo hace de la jurisdicción algo muy próximo a la "razón pública" 25 sino que también la compromete con la tarea de la permanente reinterpretación crítica entre concepciones rivales cuando se trate de asuntos que implican desacuerdos o controversias profundas, tarea que recuerda mucho, dicho sea de paso, a la propia dialéctica aristotélica como síntesis esclarecida de legomena $\mathrm{u}$ opiniones establecidas. El formalismo en este punto consiste en eludir tales exigencias bien sea considerando que es posible la neutralidad o la separación metódica entre cuestiones político-morales $\mathrm{y}$ cuestiones jurídicas, bien creyendo que las justificaciones sustantivas quedan satisfechas $-\mathrm{y}$ no disimuladas - meramente con consideraciones de orden técnico-formal y nunca "filosóficas".

xi) La práctica judicial se subordina enteramente al valor de justicia. Por expresarlo con las palabras del Código Iberoamericano de

${ }^{24}$ R. DWORKIN, “¿Deben nuestros jueces ser filósofos? ¿Pueden ser filósofos?”, Isonomía, 2010/32: 7-29 (trad. L. García Jaramillo).

25 Cf. M. ATIENZA, Curso de argumentación jurídica, Madrid, Trotta, 2013, pp. 621ss. ética judicial (art. 35): "El fin último de la actividad judicial es realizar la justicia por medio del derecho"26. Esto pone bajo el foco la excelencia de su desempeño, su carácter virtuoso. La conexión de la equidad con la virtud no es sólo relevante por su relación con la prudencia (la phronēsis propia y específica del juez, dikastikē, consistente en el acomodo mutuo del juicio normativo universal y la particularidad del caso); ni tampoco sólo por su relación con las restantes virtudes que gobiernan el ejercicio de la equidad en tanto propia del "buen juicio" (imparcialidad, independencia, discernimiento, comprensión, sobriedad, coraje cívico, etc. $)^{27}$ y que han hecho

${ }^{26}$ El Cap. V del citado Código, cuyo título es "Justicia y equidad", está inspirado directamente (a través de Atienza, quien intervino en su redacción) en la concepción aristotélica. No me resisto a reproducir, por su pertinencia, los 5 artículos restantes que lo componen: Art. 36: "La exigencia de equidad deriva de la necesidad de atemperar, con criterios de justicia, las consecuencias personales, familiares o sociales desfavorables surgidas por la inevitable abstracción y generalidad de las leyes"; Art. 37: "El juez equitativo es el que, sin transgredir el Derecho vigente, toma en cuenta las peculiaridades del caso y lo resuelve basándose en criterios coherentes con los valores del ordenamiento y que puedan extenderse a todos los casos sustancialmente semejantes"; Art. 38: "En las esferas de discrecionalidad que le ofrece el Derecho, el juez deberá orientarse por consideraciones de justicia y de equidad"; Art. 39: "En todos los procesos, el uso de la equidad estará especialmente orientado a lograr una efectiva igualdad de todos ante la ley"; Art. 40: "El juez debe sentirse vinculado no sólo por el texto de las normas jurídicas vigentes, sino también por las razones en las que ellas se fundamentan".

27 Cf. Ét. Nic., VI, 10. Cf. L.B. SOLUM, "Virtue Jurisprudence: Towards an Aretaic Theory of Law" [2003] y T. RALLI, "Intellectual Excellences of the Judge", en L. HUPPES-CLUYSENAER y N.M.M.S. COELHO (eds.), Aristotle and The Philosophy of Law: Theory, Practice and Justice, Dordrecht, Springer, 2013, pp. 1-31 (esp. 15ss.) y 135-147 (esp. 140ss.); A. AMAYA, Virtudes judiciales y argumentación. Una aproximación a la ética jurídica, México, Tribunal Electoral del Poder Judicial de la 
Cuadernos Electrónicos de Filosofía del Derecho

que la epieikeia haya sido traducida como "sensatez" (Racionero), “decencia” (Irwin), "razonabilidad" (Broadie)...; sino, sobre todo, por su directa conexión con la virtud de la justicia misma en cuanto que tiene que ver con valores objetivos (entre ellos la igualdad o la libertad, como vimos). La cuestión clave aquí es que la práctica del juicio sólo tiene sentido desde la hipótesis de tal objetividad. Es decir, asumiendo el ideal regulativo de que el juez debe recabar la "mejor respuesta posible" a la luz de los materiales jurídicos y la práctica establecida, y que dicha respuesta está de algún modo determinada dentro de esta práctica, por más que sea incierta y deba, por tanto, ser construida y argumentada desde las mejores justificaciones teóricas disponibles ${ }^{28}$. En esta tesitura, sería formalista toda posición contraria al objetivismo y cognoscitivismo de los valores, esto es, el escepticismo y el relativismo axiológicos. Posiciones que emergen siempre que se propende a desligar las excelencias o virtudes anteriores (y por tanto, los valores objetivos en ellas implicados) de la posición institucional del juez para remitirlas (como manifestaciones de la siempre deseable pero jurídicamente contingente

Federación, 2009; M. ATIENZA, "Virtudes judiciales. Selección y formación de los jueces en el Estado de Derecho", Claves de razón práctica, 1998/86: 32-42.

28 R. DWORKIN, Justice for Hedgehogs, Cambridge, Harvard UP, 2011, pp. 91, 327-415. "equidad" del juez) al plano del comportamiento puramente individual o de la moralidad subjetiva; y xii) La equidad es universalizable. Podemos entender ahora mejor el sentido del texto de Aristóteles cuando dice, por un lado, que la equidad es una mejor y superior forma de justicia que la justicia legal (es decir, que el derecho en cuanto simplemente un sistema de reglas universales), y por otro, que no pertenece sin embargo a otro género diferente y sigue siendo una forma de justicia. Lo primero es el resultado de considerar vinculado al juez no sólo por reglas sino también por las razones derivadas de los principios y valores a ellas conexos. Lo segundo significa que la equidad, si bien consiste en referirse a casos particulares (en los cuales esas razones se suscitan, pues los conflictos de normas y principios surgen en las situaciones arrojadas por la práctica social y no in abstracto), no por ello deja de ser solidaria de estándares generales. No es una "justicia del cadí", salomónica, solipsista o "particularista" (Aristóteles distingue perfectamente la equidad del juez de derecho de la equidad del árbitro: cf. Ret., I, 13, 1374b23), ya que la ponderación de valores con ocasión de un caso singular desemboca siempre, si entraña una genuina justificación, en el reconocimiento de una nueva regla que cubra todos los casos relevantemente similares para el futuro. Sin reglas no es posible la justicia en absoluto, pues no lo son tampoco las ideas de universalidad, igualdad 
Cuadernos Electrónicos

de Filosofía del Derecho

y corrección que la constituyen. Una modalidad de formalismo opuesto al de las reglas, pero tampoco infrecuente ni tan alejado de él, consiste precisamente en la pura apelación "fundamentalista" a principios o valores en sí mismos, a la "justicia absoluta". La "racionalidad" de tales valores "absolutos", sin embargo, desvinculada de la práctica y vacía de reglas en las que concretarse, está condenada a carecer por completo de la recurrencia y coherencia que caracterizan a la justicia política de un sistema de derecho. 
FERRAJOLI, Derecho y razón [1989], trad. P. Andrés et al., Madrid: Trotta 2000.

Cuadernos Electrónicos de Filosofía del Derecho

\section{Referencias}

AGUILÓ, J., "Fuentes del Derecho", en Enciclopedia de Filosofía y Teoría del Derecho, México: UNAM 2014, vol. 2, pp. 1-53.

ALEXY, R., "Los derechos fundamentales en el Estado constitucional", en M. CARBONELL, Neoconstitucionalismo(s), Madrid: Trotta 2003, pp. 31-47.

AMAYA, A., Virtudes judiciales $y$ argumentación. Una aproximación a la ética jurídica, México: Tribunal Electoral del Poder Judicial de la Federación 2009.

ARISTÓTELES, Ética nicomáquea, ed. de M. Araujo y J. Marías, Madrid: CEPC 2009, 9ª ed.

ATIENZA, M., "Virtudes judiciales. Selección y formación de los jueces en el Estado de Derecho", Claves de razón práctica, 1998/86: 32-42.

- Curso de argumentación jurídica, Madrid: Trotta 2013.

ATIENZA, M. y GARCÍA AMADO, J. A., Un debate sobre la ponderación, Lima: Palestra 2012.

ATIENZA, M. y RUIZ MANERO, J., Ilícitos atípicos. Sobre el abuso del derecho, el fraude de ley y la desviación de poder, Madrid: Trotta 2000.

AUBENQUE, P., La prudencia en Aristóteles [1963], trad. de $\mathrm{M}^{\mathrm{a}}$. J. Torres, Barcelona: Crítica 1999.

DWORKIN, R., Law's Empire, Harvard, Belknap Press, 1986.

- “Deben nuestros jueces ser filósofos? ¿Pueden ser filósofos?”, Isonomía, 2010/32: 7-29 (trad. L. García Jaramillo).

- Justice for Hedgehogs, Cambridge: Harvard University Press: 2011.
- "Constitucionalismo principialista y constitucionalismo garantista", Doxa, 34 (2011): $15-53$

GÜNTHER, K., "Un concepto normativo de coherencia para una teoría de la argumentación jurídica", Doxa, 1995/17-18: 271-302.

KANT, I., Sobre la paz perpetua, trad. J. Abellán, Madrid: Tecnos 1998.

LANNI, A., Law and Justice in the Courts of Classical Athens, New York: Cambridge University Press 2006.

LAPORTA, F. J., El imperio de la ley. Una visión actual, Madrid: Trotta 2009.

MILLER, F. D., “Aristotle's Philosophy of Law”, en F. D. MILLER, P. G. STEIN y A. PADOVANI (eds.), A History of the Philosophy of Law from the Ancient Greeks to the Scholastics, Dordrecht: Reidel 2007, pp. 79-110.

NINO, C., La validez del derecho [1985], Buenos Aires: Astrea 2006.

RALLI, T., "Intellectual Excellences of the Judge", en L. HUPPES-CLUYSENAER y N.M.M.S. COELHO (eds.), Aristotle and The Philosophy of Law: Theory, Practice and Justice, Dordrecht: Springer 2013, pp. 135-147.

RAZ, J., The Authority of Law. Essays on Law and Morality [1979], New York: Oxford University Press 1983.

RUIZ MANERO, J., "Las virtudes de las reglas y la necesidad de los principios. Algunas acotaciones a Francisco Laporta", en F. J. LAPORTA, J. RUIZ MANERO y M. A. RODILLA, Certeza y predecibilidad de las relaciones jurídicas, Madrid: Fundación Coloquio Jurídico Europeo 2009, pp. 95-123. 
SCHAUER, F., Playing by the Rules [1991], New York: Oxford University Press 2002. SOLUM, L. B., "Virtue Jurisprudence: Towards an Aretaic Theory of Law" [2003] en L. HUPPES-CLUYSENAER y N.M.M.S. COELHO (eds.), Aristotle and The Philosophy of Law, cit., pp. 1-31.
VOLPI, F., "Rehabilitación de la filosofía práctica y neo-aristotelismo", Anuario Filosófico, 1999/32: 315-342 (trad. R. Vigo).

WALLACH, J. R., "Contemporary Aristotelianism”, Political Theory, 20/4 (1992), pp. 613-641. 